\title{
Experimental Design Methodology for Simultaneous Determination of Anti-Diabetic Drugs by Reverse Phase Liquid Chromatographic Method
}

\author{
V. BUKKAPATNAM*, MUKTHINUTHALAPATI MATHRUSRI ANNAPURNAAND K. C. ROUTHU \\ Department of Pharmaceutical Analysis \& Quality Assurance, GITAM Institute of Pharmacy, GITAM University, Visakhapatnam \\ 530045, India
}

Bukkapatnam et al.: Experimental Design Methodology for Anti-Diabetic Drugs

\begin{abstract}
A liquid chromatographic method has been established for the separation of metformin, glipizide, gliclazide, glibenclamide and glimepiride using experimental design. The main intention of this method is to optimize suitable chromatographic conditions for the proper elution of the drug molecules with minimal analysis time. The relationship between the individual and combined effect of critical process parameters and chromatographic efficiency was made clear and was achieved with the aid of experimental design methodology. Waters Sunfire C18 type column $(150 \times 4.6 \mathrm{~mm}, 5 \mu \mathrm{m}$ particle size) was employed and 0.1 $\%$ acetic acid in water: acetonitrile mixture was adopted as mobile phase (flow rate: $0.469 \mathrm{ml} / \mathrm{min}$ ) for the separation of analytes. The developed method was validated and has been extended for the assay of marketed formulations.
\end{abstract}

Key words: Anti-diabetic drugs, design of experiments, quality by design, liquid chromatographic method, International Council on Harmonisation guidelines

Diabetes has developed as a common disease now a days and Type II diabetes (non-insulin-dependent) is majorly a result of interaction between genetic, behavioural risk and environmental factors. The combination of metformin (MFM) with second generation sulfonylureas is very common now a days in the available marketed formulations for the treatment of Type II diabetes ${ }^{[1,2]}$. MFM, a plagiaristic biguanide is a hypoglycemic agent. MFM is chemically known as 3-(diaminomethylidene)-1,1-dimethyl guanidine $\left(\mathrm{C}_{4} \mathrm{H}_{11} \mathrm{~N}_{5}\right.$; Molecular weight: $\left.129.16 \mathrm{~g} / \mathrm{mol}\right)$. Glipizide (GPZ) is a short-acting, $2^{\text {nd }}$ generation plagiaristic sulfonylurea with hypoglycemic activity. It is chemically N-(2-\{4-[(Cyclohexylcarbamoyl) sulfamoyl] phenyl $\}$ ethyl)-5-methyl-2-pyrazinecarboxamide $\left(\mathrm{C}_{21} \mathrm{H}_{27} \mathrm{~N}_{5} \mathrm{O}_{4} \mathrm{~S}\right.$; Molecular weight: $445.54 \mathrm{~g} / \mathrm{mol}$ ). Gliclazide (GCZ) is a second generation sulfonylurea plagiaristic with hypoglycemic activity. It is chemically, $1-(3,3 a, 4,5,6,6 a-$ hexahydro-1H-cyclopenta [c]pyrrol-2-yl)-3(4-methylphenyl)sulfonylurea $\left(\mathrm{C}_{15} \mathrm{H}_{21} \mathrm{~N}_{3} \mathrm{O}_{3} \mathrm{~S}\right.$; Molecular weight: $323.41 \mathrm{~g} / \mathrm{mol})$. Glibenclamide $(\mathrm{GBM})$ is a plagiaristic sulfonylurea used as an anti-hyperglycemic agent. It is chemically known as 5-chloro-N-[2[4-(cyclohexylcarbamoylsulfamoyl)phenyl] ethyl]-

*Address for correspondence

E-mail: venki.b11@gmail.com

May-June 2021 2-methoxybenzamide $\quad\left(\mathrm{C}_{23} \mathrm{H}_{28} \mathrm{ClN}_{3} \mathrm{O}_{5} \mathrm{~S} ; \quad\right.$ Molecular weight: $494.00 \mathrm{~g} / \mathrm{mol}$ ). Glimepiride (GMP) is a third generation sulfonylurea with hypoglycemic activity and is a very potent drug that has reported a longer duration of action in comparison with other generations of sulfonylurea compounds. Chemically it is known as 4-ethyl-3-methyl-N-[2-[4-[(4-methylcyclohexyl) carbamoylsulfamoyl]phenyl]ethyl]-5-oxo-2H-pyrrole1-carboxamide $\left(\mathrm{C}_{24} \mathrm{H}_{34} \mathrm{~N}_{4} \mathrm{O}_{5} \mathrm{~S}\right.$; Molecular weight: $490.62 \mathrm{~g} / \mathrm{mol})$. The structures are illustrated on fig. 1 .

The optimization of chromatographic methods is often very complex while dealing with combination of compounds due to different variables. The chromatographic separations are mostly based on trial and error procedures. This traditional approach involves the study of the influence of corresponding variables by changing one variable at a time (OVAT)

This is an open access article distributed under the terms of the Creative Commons Attribution-NonCommercial-ShareAlike 3.0 License, which allows others to remix, tweak, and build upon the work non-commercially, as long as the author is credited and the new creations are licensed under the identical terms 


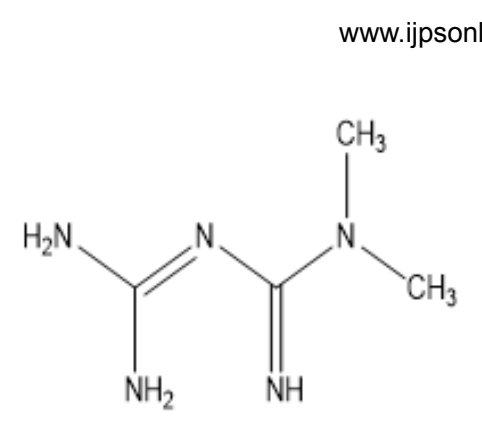

(a)

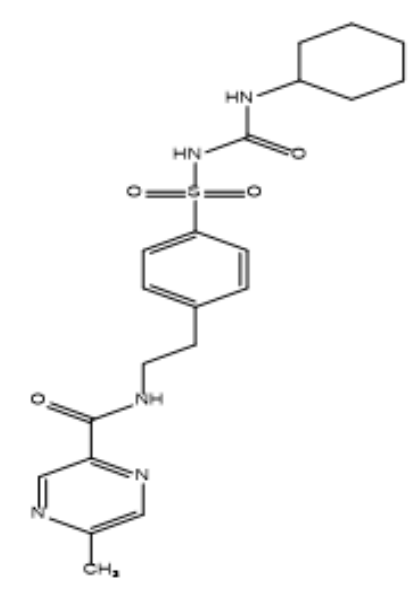

(b)

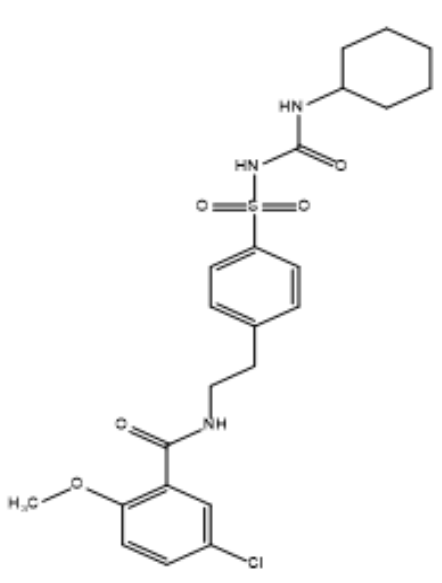

(d)

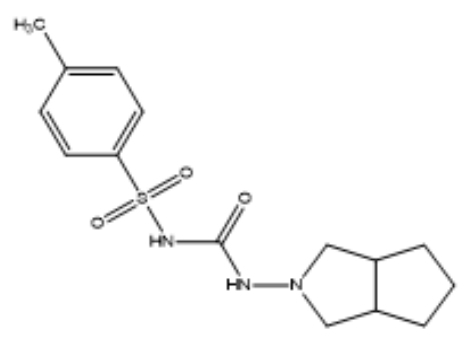

(c)

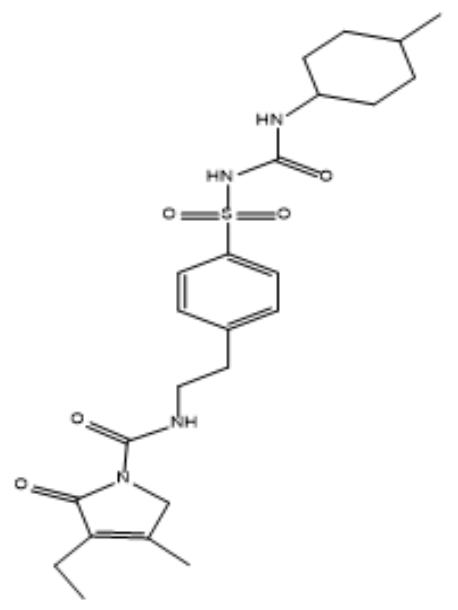

(e)

Fig. 1: Structural representation of (a) MFM, (b) GPZ, (c) GCZ, (d) GBM and (e) GMP

while keeping the other variables constant. The major disability of these methods is time consuming as it requires a greater number of trial experiments with no predicted conditions and therefore unable to predict the conceivable interactions within the factors on the responses.

In such separations, the method can be optimized at its best by employing quality by design (QbD) which is a systematized approach for the development of an analytical method that incorporates multifaceted combinations of independent variables and their interactions by applying design of experiments (DoE), to obtain optimal experimental conditions. DoE also provides an inference on possibility of understanding and also to mark the variables which majorly affects the method performance. As reported by International Council on Harmonisation (ICH) guideline Q8(R2) ${ }^{[3]}$, the $\mathrm{QbD}$ approach is a defined optimization approach combining the DoE and Design Space (DS). As per the guidelines DS is defined as the multidimensional combination and interaction of input variables (e.g. material attributes) and process parameters that have been demonstrated to provide assurance of quality. Both graphical (overlay contour plots and three-dimensional (3D) plots) and mathematical (Derringer's desirability function) functions are involved in the approach of better method optimization ${ }^{[4-8]}$.

Few methods have been proclaimed in the literature for the determination of various combinations of antidiabetic drugs in human plasma and pharmaceutical dosage forms which include thin layer chromatography (TLC) $)^{[9]}$, high performance liquid chromatography (HPLC) $)^{[10-15]}$ and liquid chromatography-tandem mass spectrometry (LC-MS/MS $)^{[16]}$. No method with the aid of DoE, has been developed till now for the simultaneous determination of MFM, GPZ, GCZ, GBM and GMP. Therefore, the authors have made an attempt to develop a validated chromatographic method with the help of Central Composite Design (CCD), as a model for DoE and to apply the same for the assay of available marketed combined dosage formulations in India.

\section{MATERIALS AND METHODS}

\section{Instrumentation and chromatographic conditions:}

HPLC system: Ultra-Fast Liquid Chromatograph (UFLC) Shimadzu Prominence system (CBM-20Alite) model; SPD M20A detector (Photodiode-Array (PDA))

Stationary Phase: Waters Sunfire C18-type column $(150 \times 4.6 \mathrm{~mm} ; 5 \mu \mathrm{m}$ particle size $)$ 
Mobile Phase: $0.1 \%$ acetic acid in water and acetonitrile (ACN) (32.9:67.1, \% v/v) (Isocratic mode)

Flow rate: $0.469 \mathrm{ml} / \mathrm{min}$

Injection volume: $20 \mu 1$

Ultraviolet/visible light (UV) detection

Wavelength: $230 \mathrm{~nm}$

Temperature: Ambient (about 25)

\section{Software and data pre-handling:}

The datamanagement software Shimadzu's LC Solutions v1.25 (Kyoto, Japan) was used to monitor, integrating and processes the chromatographic responses. For the experimental designs and the selection of the runs, Design Expert 10.0.2.0 trial version (Stat-Ease Inc., Minneapolis, MN, USA) has been used. The statistical interpretation for the optimization of the analytical method and effects of parameters were studied and calculated

\section{Materials and reagents:}

Reference standards of MFM (>99.1 \%), GPZ (>98\%), GCZ (>98.5\%), GBM (>98.5\%) and GMP (>99\%)were gratefully provided by Sun pharmaceutical Industries Ltd., India as gift samples.

The available marketed formulations Glipimet Forte tab $^{\circledR}$ (label claim: $500 \mathrm{mg} / 5 \mathrm{mg}$ MFM/GPZ) (Sun Pharma Laboratories Ltd., India), Diaglip-M tab ${ }^{\circledR}$ (label claim: $500 \mathrm{mg} / 5 \mathrm{mg} \mathrm{MFM} / \mathrm{GPZ}$ ) (Cipla Ltd., India), Glygard-M tab $^{\circledR}$ (label claim: $500 \mathrm{mg} / 80 \mathrm{mg}$ MFM/ GCZ) (Cipla Ltd., India), Azukon-M tab ${ }^{\circledR}$ (label claim: $500 \mathrm{mg} / 80 \mathrm{mg}$ MFM/GCZ) (Torrent Pharmaceuticals Ltd., India), Glinil-M tab ${ }^{\circledR}$ (label claim: $500 \mathrm{mg} / 5 \mathrm{mg}$ MFM/GBM) (Cipla Ltd., India), Glucored Forte tab ${ }^{\circledR}$ (label claim: $500 \mathrm{mg} / 5 \mathrm{mg}$ MFM/GBM) (Sun Pharma Laboratories Ltd., India), Azulix-MF tab ${ }^{\circledR}$ (label claim: $500 \mathrm{mg} / 2 \mathrm{mg}$ MFM/GMP) (Torrent Pharmaceuticals Ltd., India) and Gemer-2 tab ${ }^{\circledR}$ (label claim: $500 \mathrm{mg} / 2$ mg MFM/GMP) (Sun Pharma Laboratories Ltd., India) are procured from the local pharmacy and utilised for the assay of the above mentioned drugs. All chemicals were procured from Merck, India (analytical reagentAR) and used as received. Acetic acid solution $(0.1 \%)$ was prepared from glacial acetic acid using HPLC grade water, sonicated for half an hour and filtered.

All the stock solutions of MFM, GPZ, GCZ, GBM and GMP were prepared separately by transferring accurately $25 \mathrm{mg}$ of each into different $25 \mathrm{ml}$ volumetric flasks in ACN $(1000 \mu \mathrm{g} / \mathrm{ml})$ and dilutions were made with mobile phase and finally filtered through $0.45 \mu \mathrm{m}$ nylon membrane filter before injecting into the HPLC system.

\section{Validation:}

The method was validated as per the ICH guidelines ${ }^{[17]}$. For linearity study a series of drug solutions (0.01$400 \mu \mathrm{g} / \mathrm{ml}$ ) were prepared from their respective stock solutions of the raw materials, scanned and analysed. The precision studies were performed by analysing each drug solution at different levels $(5,10$ and $20 \mu \mathrm{g} / \mathrm{ml})$ at different intervals on the same day (intra-day) and on three different days (inter-day) respectively. Accuracy studies were conducted by calculating the percentage recovery for the solutions prepared by spiking with pre-analysed samples for all the five drugs. Robustness study was performed $(10 \mu \mathrm{g} / \mathrm{ml})$ by modifying slightly the chromatographic conditions such as flow rate, mobile phase ratio and detection wavelength. The solution stability was performed for $24 \mathrm{~h}$, by storing the stock solution in a tightly capped volumetric flask at $4-8^{\circ}$. Mobile phase bench top stability was assessed by assaying the freshly prepared sample solutions against freshly prepared reference standard solutions at regular intervals up to $24 \mathrm{~h}$.

\section{Assay of marketed formulations:}

Twenty tablets from each brand of the five drugs were procured from the local pharmacy store and extracted the drugs with mobile phase and the percentage recovery was calculated.

\section{RESULTS AND DISCUSSION}

Method development and optimization is carried out and the main aim of developing the reverse phase high performance liquid chromatography (RP-HPLC) method is to determine simultaneously MFM, GPZ, GCZ, GBM and GMP in bulk and as well as in pharmaceutical dosage forms which were separated from each other with good resolution ( $\mathrm{RS}>2.0)$ due to modified critical HPLC parameters. It is necessary to identify the crucial factors that can affect the separation of these drugs. During the preliminary screening different columns, several mobile phase compositions, flow rate etc. were screened in different combinations. Waters Sunfire C18 $(150 \times 4.6 \mathrm{~mm}, 5 \mu \mathrm{m})$ column was able to show proper resolution of the drugs. From this, percentage of organic phase and flow rate were identified as critical variables on the chromatographic response of these five drugs with least noise. The overlay UV absorption spectrum (fig. 2) shows that the 
$230 \mathrm{~nm}$ is the suitable wavelength at which all the five drugs can be detected satisfactorily.

In the present study for the optimisation of liquid chromatographic method, the authors have chosen $\mathrm{CCD}$, which is one of the models of response surface methodology in the experimental design. Independent variables i.e., ratio of organic phase and flow rate, each at three levels were mentioned in Table 1. The levels for each factor were selected based on initial preliminary trials.

The method was fully optimized using thirteen experimental runs. The design was composed of two levels factorial design with additional centre points located at the centre of the experimental region. The influence of the above said variables on the chromatographic responses (resolution of GPZ $\left[\mathrm{Rs}_{(\mathrm{MFM}-\mathrm{GPZ})}\right]$, resolution of GCZ $\left[\mathrm{Rs}_{(\mathrm{GPZ}-\mathrm{GCZ})}\right]$, resolution

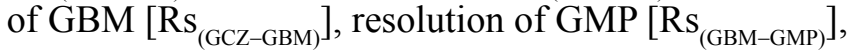
tailing factor of MFM $\left[\mathrm{T}_{\mathrm{MFM}}\right]$, tailing factor of GPZ $\left[\mathrm{T}_{\mathrm{GPZ}}\right]$, tailing factor of $\mathrm{GCZ}\left[\mathrm{T}_{\mathrm{GCZ}}\right]$, tailing factor of GBM $\left[\mathrm{T}_{\mathrm{GBM}}\right]$, tailing factor of GMP $\left[\mathrm{T}_{\mathrm{GMP}}\right]$, retention time of MFM (min) $\left[\mathrm{R}_{\mathrm{t}(\mathrm{MFM})}\right]$ and total run time (min) [total analysis time]) were investigated and shown in Table 2. The chromatograms of these trials are given in fig. S1.

The statistical parameters from the analysis of variance (ANOVA) were listed in Table 3. The probability $\mathrm{p}<0.03$ for all the chromatographic responses implies that the models are highly significant. The model has provided the high values of correlation coefficient $\left(\mathrm{R}^{2}\right)$ and adjusted $\mathrm{R}^{2}$ indicating a close relation between the experimental and the predicted values of the responses. The adequate precision measures the signal to noise ratio which was found to be $>4$ indicating that the model can be used for the prediction of perfect chromatographic conditions. The polynomial equations are given below (Eq. (1-11)) in which A: \% organic phase (\% ACN) and B: flow rate $(\mathrm{ml} / \mathrm{min})$.

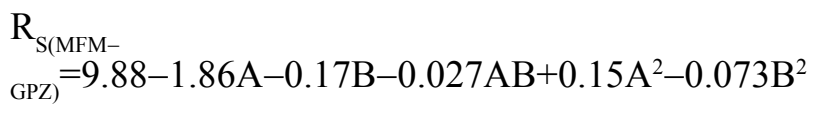

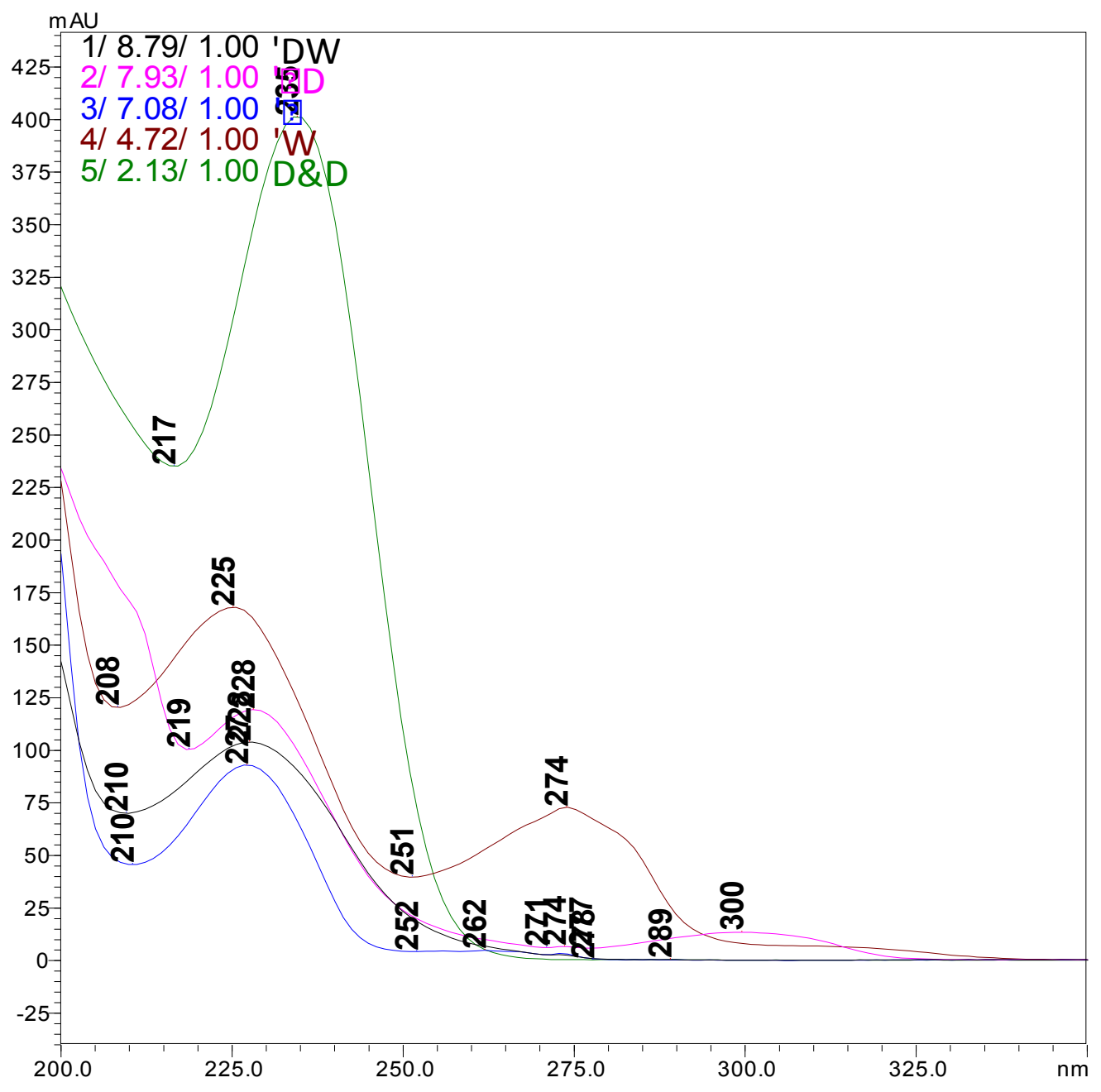

Fig. 2: Overlay UV absorption spectrum of MFM, GPZ, GCZ, GBM and GMP (10 $\mu \mathrm{g} / \mathrm{ml}$ each) 


\begin{tabular}{|c|c|c|c|}
\hline \multirow[t]{2}{*}{ Variables } & \multicolumn{3}{|c|}{ Levels } \\
\hline & -1 (Low) & 0 (Medium) & 1 (High) \\
\hline \multicolumn{4}{|l|}{ Independent } \\
\hline A- \% Organic phase (\% ACN) & 60 & 65 & 70 \\
\hline B- Flow rate (ml/min) & 0.4 & 0.5 & 0.6 \\
\hline \multicolumn{4}{|l|}{ Dependent } \\
\hline $\mathrm{R}_{\mathrm{S} \text { (MFM-GPZ) }}$ & $=$ Resolution of GPZ & & \\
\hline $\mathrm{Rs}_{(\mathrm{GPZ}-\mathrm{GCZ})}$ & $=$ Resolution of GCZ & & \\
\hline $\mathrm{Rs}_{(G C Z-G B M)}$ & $=$ Resolution of GBM & & \\
\hline $\mathrm{Rs}_{(\mathrm{GBM}-\mathrm{GMP})}$ & $=$ Resolution of GMP & & \\
\hline $\mathrm{T}_{\text {MFM }}$ & $=$ Tailing factor of MFM & & \\
\hline$T_{G P Z}$ & $=$ Tailing factor of GPZ & & \\
\hline $\mathrm{T}_{\mathrm{GCZ}}$ & $=$ Tailing factor of GCZ & & \\
\hline $\mathrm{T}_{\mathrm{GBM}}$ & $=$ Tailing factor of GBM & & \\
\hline$T_{G M P}$ & $=$ Tailing factor of GMP & & \\
\hline $\mathrm{R}_{\mathrm{t}(\mathrm{MFM})}$ & $=$ Retention time of MFM (min) & & \\
\hline Total analysis time & $=$ Total run time $(\mathrm{min})$ & & \\
\hline
\end{tabular}

TABLE 2: CONDUCTED EXPERIMENTS AND MEASURED RESPONSE VALUES FOR CCD INVOLVING THREE VARIABLES AT THREE LEVELS

\begin{tabular}{|c|c|c|c|c|c|c|c|c|c|c|c|c|c|}
\hline \multirow[b]{2}{*}{ Run } & \multicolumn{2}{|c|}{ Factors } & \multicolumn{11}{|c|}{ Responses } \\
\hline & A & B & $\mathbf{R}_{\mathrm{S} \text { (MFM-GPZ) }}$ & $\mathbf{R s}_{(\mathrm{GPZ}-\mathrm{GCZ})}$ & $\mathbf{R s}_{(\mathrm{GCZ}-\mathrm{GBM})}$ & $\mathbf{R s}_{(G B M-G M P)}$ & $\mathrm{T}_{\text {MFM }}$ & $\mathrm{T}_{\mathrm{GPZ}}$ & $\mathrm{T}_{\mathrm{GCZ}}$ & $\mathrm{T}_{\mathrm{GBM}}$ & $T_{G M P}$ & $\mathbf{R}_{\mathrm{t}(\mathrm{MFM})}$ & $\begin{array}{c}\text { Total } \\
\text { analysis } \\
\text { time }\end{array}$ \\
\hline 1 & 60 & 0.6 & 11.676 & 10.091 & 4.828 & 3.052 & 0.969 & 1.103 & 1.184 & 1.095 & 1.07 & 1.641 & 10.237 \\
\hline 2 & 65 & 0.641 & 9.49 & 8.495 & 3.054 & 2.474 & 0.984 & 1.112 & 1.23 & 1.123 & 1.094 & 1.54 & 7.169 \\
\hline 3 & 57.9 & 0.5 & 12.846 & 11.166 & 5.778 & 3.215 & 0.904 & 1.103 & 1.207 & 1.094 & 1.07 & 1.988 & 14.15 \\
\hline 4 & 65 & 0.5 & 9.881 & 8.932 & 3.193 & 2.604 & 0.949 & 1.137 & 1.231 & 1.126 & 1.1 & 1.962 & 9.137 \\
\hline 5 & 70 & 0.4 & 8.158 & 7.408 & 1.929 & 2.269 & 0.951 & 1.223 & 1.584 & 1.178 & 1.141 & 2.463 & 8.995 \\
\hline 6 & 70 & 0.6 & 7.854 & 6.855 & 1.842 & 2.112 & 0.95 & 1.156 & 1.387 & 1.166 & 1.116 & 1.638 & 6.058 \\
\hline 7 & 72.1 & 0.5 & 7.631 & 6.578 & 1.522 & 2.055 & 0.909 & 1.209 & 1.31 & 1.264 & 1.126 & 1.973 & 6.563 \\
\hline 8 & 65 & 0.359 & 10.111 & 9.169 & 3.174 & 2.705 & 1.02 & 1.194 & 1.277 & 1.173 & 1.135 & 2.729 & 12.545 \\
\hline 9 & 60 & 0.4 & 11.872 & 10.555 & 4.827 & 3.043 & 0.944 & 1.107 & 1.238 & 1.127 & 1.096 & 2.0469 & 15.176 \\
\hline
\end{tabular}

$\mathrm{Rs}_{(\mathrm{GPZ}-\mathrm{GCZ})}=8.93-1.61 \mathrm{~A}-0.25 \mathrm{~B}-0.022 \mathrm{AB}-0.06 \mathrm{~A}^{2} 0.08 \quad \mathrm{~T}_{\mathrm{GCZ}}=1.26+0.09 \mathrm{~A}-0.04 \mathrm{~B}$

$2 \mathrm{~B}^{2}$

(2)

$\mathrm{Rs}_{(\mathrm{GCZ}-}$

GBM) $=3.19-1.48 \mathrm{~A}-0.032 \mathrm{~B}-0.022 \mathrm{AB}+0.22 \mathrm{~A}^{2}-0.046 \mathrm{~B}^{2}$

$\mathrm{Rs}_{(\mathrm{GBM}-\mathrm{GMP})}=2.61-0.42 \mathrm{~A}-0.059 \mathrm{~B}-0.041 \mathrm{AB}$

$\mathrm{T}_{\text {MFM }}=0.95-0.0006 \mathrm{~A}-0.003 \mathrm{~B}-0.007 \mathrm{AB}-0.021 \mathrm{~A}^{2}$

$+0.026 \mathrm{~B}^{2}$

$\mathrm{T}_{\mathrm{GPZ}}=1.14+0.04 \mathrm{~A}-0.02 \mathrm{~B}-0.016 \mathrm{AB}+0.008 \mathrm{~A}^{2}+0.006 \mathrm{~B}^{2}$
$\mathrm{T}_{\mathrm{GBM}}=1.14+0.05 \mathrm{~A}-0.014 \mathrm{~B}$

$\mathrm{T}_{\mathrm{GMP}}=1.10+0.021 \mathrm{~A}-0.014 \mathrm{~B}+0.0003 \mathrm{AB}-0.001 \mathrm{~A}^{2}$ $+0.007 \mathrm{~B}^{2}$

$\mathrm{R}_{\mathrm{t}(\mathrm{MFM})}=1.99+0.05 \mathrm{~A}-0.36 \mathrm{~B}$

Total run time $=9.14-2.63 \mathrm{~A}-1.94 \mathrm{~B}+0.50 \mathrm{AB}+0.61 \mathrm{~A}^{2}+$ $0.37 \mathrm{~B}^{2}$

(4) The positive value indicates the favourable response and negative value indicates the inverse effect between

(5) the variable and the response in the equation. From these equations it is clear that the buffer strength (A) has positive effect on $\mathrm{T}_{\mathrm{GPZ}}, \mathrm{T}_{\mathrm{GCZ}}, \mathrm{T}_{\mathrm{GBM}}, \mathrm{T}_{\mathrm{GMP}}$ and $\mathrm{R}_{\mathrm{t}(\mathrm{MFM})}, \%$ organic phase (B) shows negative effect on all the responses. 
www.ijpsonline.com

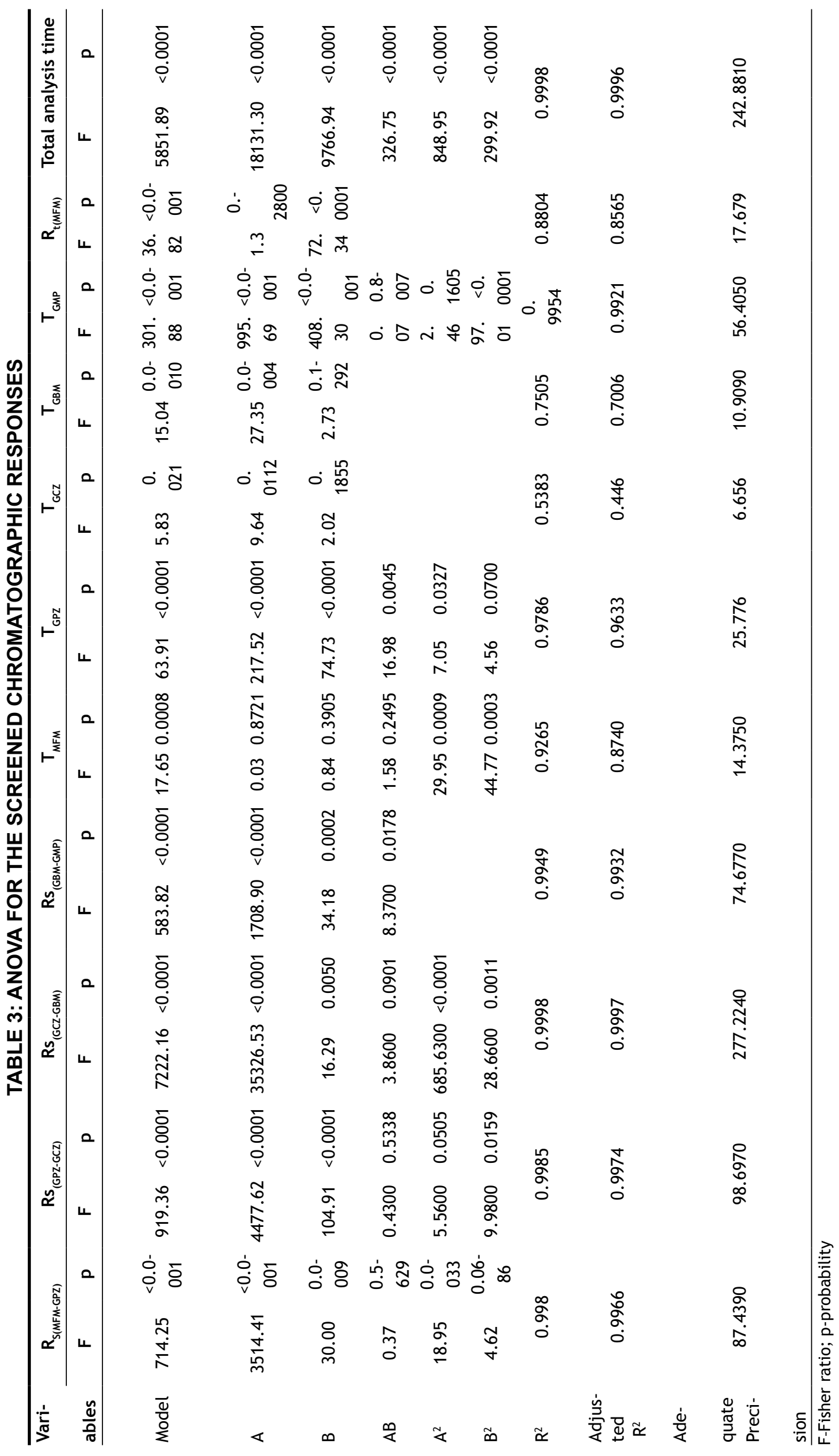


It is evident that the relation between the independent variables for $\mathrm{R}_{\mathrm{S}(\mathrm{MFM}-\mathrm{GPZ})}, \mathrm{Rs}_{(\mathrm{GPZ}-\mathrm{GCZ})}, \mathrm{Rs}_{(\mathrm{GCZ}-\mathrm{GBM})}, \mathrm{T}_{\mathrm{MFM}}$, $\mathrm{T}_{\mathrm{GPZ}}, \mathrm{T}_{\mathrm{GMP}}$ and total analysis time is quadratic. Whereas, it is linear in case of $\mathrm{T}_{\mathrm{GCZ}}, \mathrm{T}_{\mathrm{GBM}}, \mathrm{R}_{\mathrm{t}(\mathrm{MFM})}$ and 2FI model for $\mathrm{Rs}_{(\mathrm{GBM}-\mathrm{GMP})}$.

The perturbation plots are represented in fig. S2 which describes the effect of the independent variables on specific response with all other variables held constant at a reference point. 3D response surface plots (fig. 3) and Contour plots (fig. S3), portray the combined effect of both organic phase and flow rate on the responses, which were very much useful for studying the interaction effect of variables on the responses. From these it is evident that most of the responses are very much sensitive towards variable A, showing negative effect for
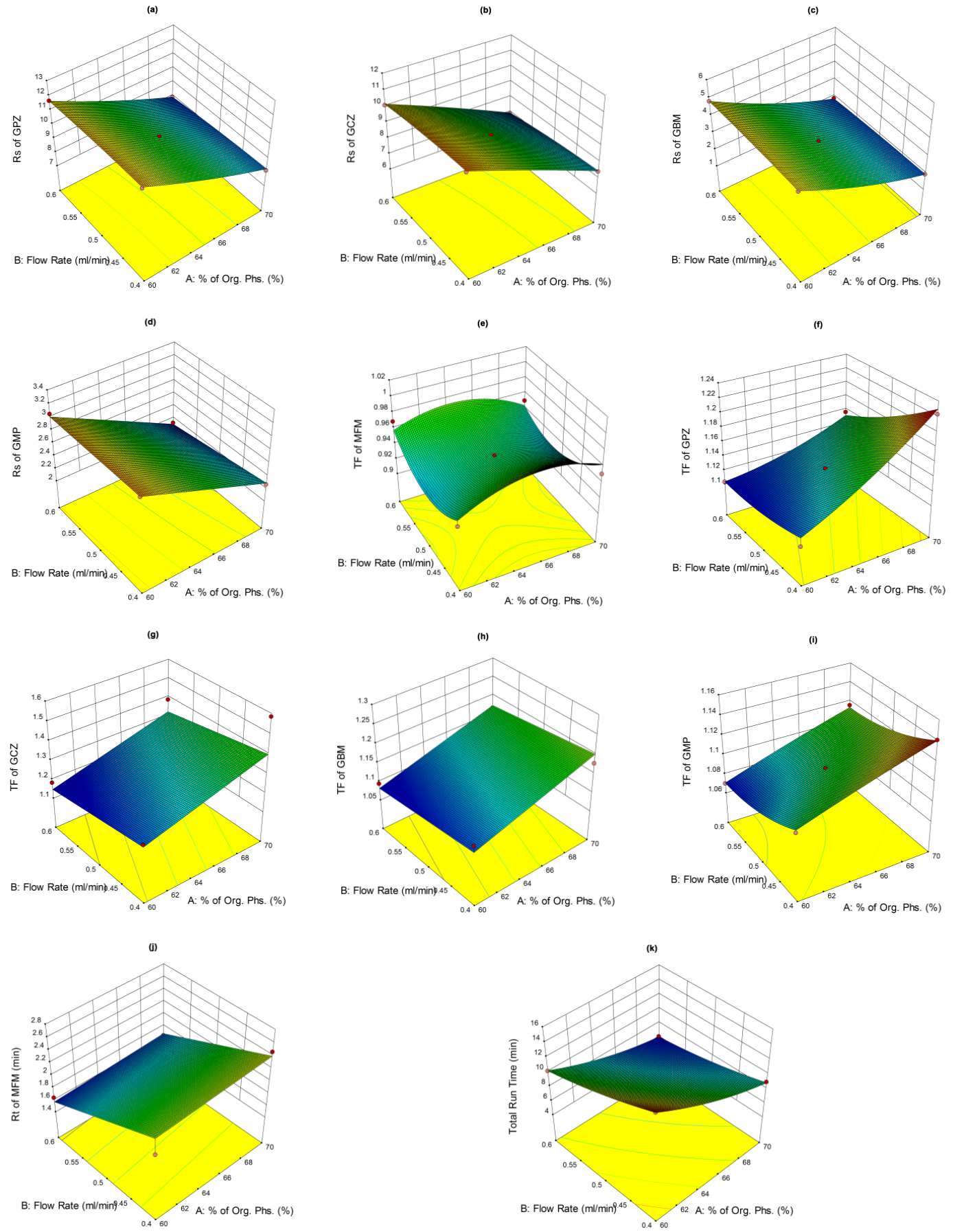

Fig. 3: Response surface plots depicting the influence of the combined effect of \% Organic phase (\% ACN) (A) and flow rate (ml/ min) (B) on (a) $R s_{(M F M-G P)}$, (b) $R_{(G P Z-G C Z)}$, (c) $R s_{(G C Z-G B M)}$, (d) $R s_{(G B M-G M P)}$, (e) $T_{M F M}$, (f) $T_{G P Z},(g) T_{G C Z}$, (h) $T_{G B M}$, (i) $T_{G M P}$, (j) $R_{t(M F M)}$ and (k) total analysis time 
$\mathrm{Rs}_{(\mathrm{MFM}-\mathrm{GPZ})}, \mathrm{Rs}_{(\mathrm{GPZ}-\mathrm{GCZ})}, \mathrm{Rs}_{(\mathrm{GCZ}-\mathrm{GBM})}, \mathrm{Rs}_{(\mathrm{GBM}-\mathrm{GMP})}$ and total run time indicating that increasing levels of $A$ results in decreased response, on the other hand $\mathrm{T}_{\mathrm{GPZ}}, \mathrm{T}_{\mathrm{GCZ}}, \mathrm{T}_{\mathrm{GBM}}$, $\mathrm{T}_{\mathrm{GMP}}$ responded positively for increasing levels of $\mathrm{A}$. In case of $\mathrm{T}_{\mathrm{MFM}}$, both increasing and decreasing levels of variable A shows negative effect, showing maximum response at the reference point. Increasing levels of Variable $B$ shows negative effect on $\mathrm{T}_{\mathrm{GPZ}}, \mathrm{T}_{\mathrm{GBM}}, \mathrm{T}_{\mathrm{MFM}}$ and total run time. In case of $\mathrm{T}_{\mathrm{MFM}}$, both the higher and lower levels of variable B show increased response, while other responses were no much effected.

TABLE 4: DESIRABILITY CRITERIA FOR OPTIMIZED INDIVIDUAL RESPONSES

\begin{tabular}{lccc}
\hline Name & Goal & Lower limit & Upper limit \\
\hline $\mathrm{R}_{\text {S(MFM-GPZ) }}$ & is in range & 7.631 & 12.846 \\
$\mathrm{Rs}_{\text {(GPZ-GCZ) }}$ & is in range & 6.578 & 11.166 \\
$\mathrm{Rs}_{\text {(GCZ-GBM) }}$ & is in range & 2.000 & 5.778 \\
$\mathrm{Rs}_{\text {(GBM-GMP) }}$ & is in range & 2.055 & 3.215 \\
$\mathrm{~T}_{\text {MFM }}$ & minimize & 0.904 & 1.020 \\
$\mathrm{~T}_{\text {GPZ }}$ & minimize & 1.103 & 1.223 \\
$\mathrm{~T}_{\text {GCZ }}$ & minimize & 1.184 & 1.584 \\
$\mathrm{~T}_{\text {GBM }}$ & minimize & 1.094 & 1.264 \\
$\mathrm{~T}_{\text {GMP }}$ & minimize & 1.070 & 1.141 \\
$\mathrm{R}_{\mathrm{t}(M F M)}$ & maximize & 1.800 & 2.729 \\
Total analysis & minimize & 6.058 & 15.176 \\
time & & &
\end{tabular}

The main objective is to separate the peaks with all system suitability parameters within the limits with minimum analysis time. Derringer's desirability function (D) is a multi-criteria decision-making tool to conciliate various responses to acquire the composition of different independent variables. The value of $\mathrm{D}$ differs from 0 to 1 meaning that the responses are in a desirable range and the value close to 1 specifically implies that the response values are near to target values. The criteria of optimization for each individual response were clearly shown in Table 4. Generally, short analysis time with good resolution and less tailing of the eluted peaks is preferred. The optimization procedure was carried out by following the conditions and the criteria provided by the design expert. The desirability of the method gives overall impression on the achievement of required criteria of each and every response.

The Desirability bar graph shown in fig. 4 demonstrates the desirability of each response at the optimised chromatographic conditions. Two runs in total have shown the maximum desirability. Percentage prediction error (PE) was calculated from Eq. 12 for each response and the mean for all the responses in every run was shown in Table 5.

\section{TABLE 5: FOR SELECTION OF THE FINAL OPTIMIZED CHROMATOGRAPHIC CONDITION}

\begin{tabular}{|c|c|c|c|c|c|c|c|}
\hline \multirow{2}{*}{ S. No } & \multicolumn{2}{|c|}{ Factors } & \multirow{2}{*}{ Responses } & \multirow{2}{*}{ Predicted values } & \multirow{2}{*}{ Observed values } & \multirow{2}{*}{ PE } & \multirow{2}{*}{ Mean PE } \\
\hline & A & B & & & & & \\
\hline \multirow{11}{*}{1} & \multirow{11}{*}{67.2} & \multirow{11}{*}{0.469} & $\mathrm{R}_{\mathrm{S} \text { (MFM-GPZ) }}$ & 9.154 & 9.217 & -0.295 & \multirow{11}{*}{-2.326} \\
\hline & & & $\mathrm{Rs}_{(\mathrm{GPZ}-\mathrm{GCZ})}$ & 8.298 & 8.169 & -1.555 & \\
\hline & & & $\mathrm{Rs}_{(\mathrm{GCZ}-\mathrm{GBM})}$ & 2.6 & 2.539 & -2.346 & \\
\hline & & & $\mathrm{Rs}_{(G B M-G M P)}$ & 2.454 & 2.490 & 1.467 & \\
\hline & & & $T_{M F M}$ & 0.949 & 0.840 & -11.486 & \\
\hline & & & $\mathrm{T}_{\mathrm{GPZ}}$ & 1.166 & 1.159 & -0.600 & \\
\hline & & & $\mathrm{T}_{\mathrm{GCZ}}$ & 1.325 & 1.235 & -6.792 & \\
\hline & & & $T_{G B M}$ & 1.166 & 1.137 & -2.487 & \\
\hline & & & $\mathrm{T}_{G M P}$ & 1.114 & 1.104 & -0.898 & \\
\hline & & & $R_{t(M F M)}$ & 2.123 & 2.118 & -0.236 & \\
\hline & & & Total analysis time & 8.69 & 8.659 & -0.357 & \\
\hline \multirow{11}{*}{$2^{*}$} & \multirow{11}{*}{67.1} & \multirow{11}{*}{0.468} & $\mathrm{R}_{\mathrm{S}(\mathrm{MFM}-\mathrm{GPZ})}$ & 9.167 & 9.317 & 1.636 & \multirow{11}{*}{-2.261} \\
\hline & & & $\mathrm{Rs}_{(\mathrm{GPZ}-\mathrm{GCZ})}$ & 8.31 & 8.362 & 0.626 & \\
\hline & & & $\mathrm{Rs}_{(\mathrm{GCZ}-\mathrm{GBM})}$ & 2.61 & 2.569 & -1.571 & \\
\hline & & & $\mathrm{Rs}_{(\mathrm{GBM}-\mathrm{GMP})}$ & 2.457 & 2.415 & -1.709 & \\
\hline & & & $\mathrm{T}_{\text {MFM }}$ & 0.949 & 0.821 & 13.448 & \\
\hline & & & $\mathrm{T}_{\mathrm{GPZ}}$ & 1.165 & 1.14 & -2.146 & \\
\hline & & & $\mathrm{T}_{\mathrm{GCZ}}$ & 1.324 & 1.249 & -5.665 & \\
\hline & & & $\mathrm{T}_{G B M}$ & 1.166 & 1.133 & -2.830 & \\
\hline & & & $\mathrm{T}_{G M P}$ & 1.114 & 1.101 & -1.167 & \\
\hline & & & $\mathrm{R}_{\mathrm{t}(\mathrm{MFM})}$ & 2.125 & 2.129 & 0.377 & \\
\hline & & & Total analysis time & 8.732 & 8.794 & 1.069 & \\
\hline
\end{tabular}

${ }^{*}$ Indicates the optimum condition with least mean PE 
Percentage prediction error $(\mathrm{PE})=$ Observed-Predicted/ Predicted $\times 100 \quad$ (12)

The runs were scrutinized based on the mean percentage PE and the run (run 2) with least PE value was nominated as the desired method. The DS plot (fig. 5) revealed that, the so obtained optimized method had fallen within the DS.

Finally, the optimised chromatographic condition was racked up with a mobile phase comprising of $0.1 \%$ acetic acid in water and ACN (32.9:67.1\% v/v) and flow rate $0.469 \mathrm{ml} / \mathrm{min}$. At this optimised condition, MFM, GPZ, GCZ, GBM and GMP were eluted at $2.129,4.718,7.076,7.927$ and 8.794 min respectively. The subsequent typical chromatograms for the mixture, individual standard chromatograms were shown in fig. 6. From the overall optimization, it was properly identified that most of the variables have been fully attained as per the requirement while some variables have been slightly attained but within the limit. On the

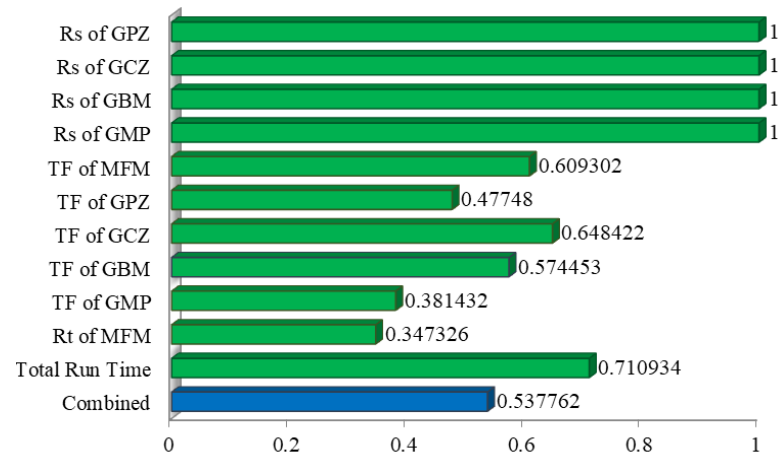

Fig. 4: The desirability bar graph for the chromatographic responses at the optimized condition

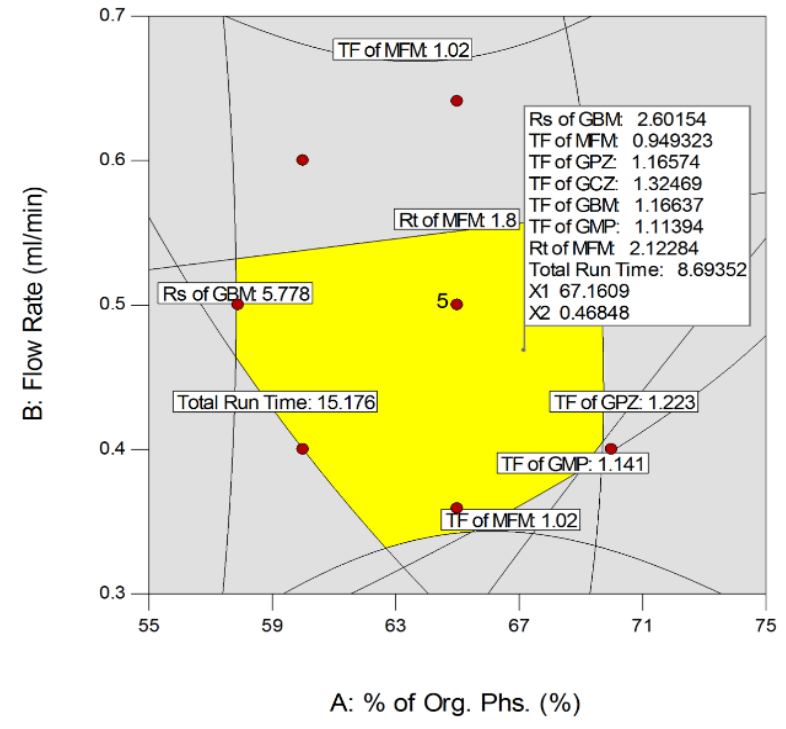

Fig. 5: The design space for the final optimized chromatographic condition

May-June 2021

Indian Journal of Pharmaceutical Sciences 


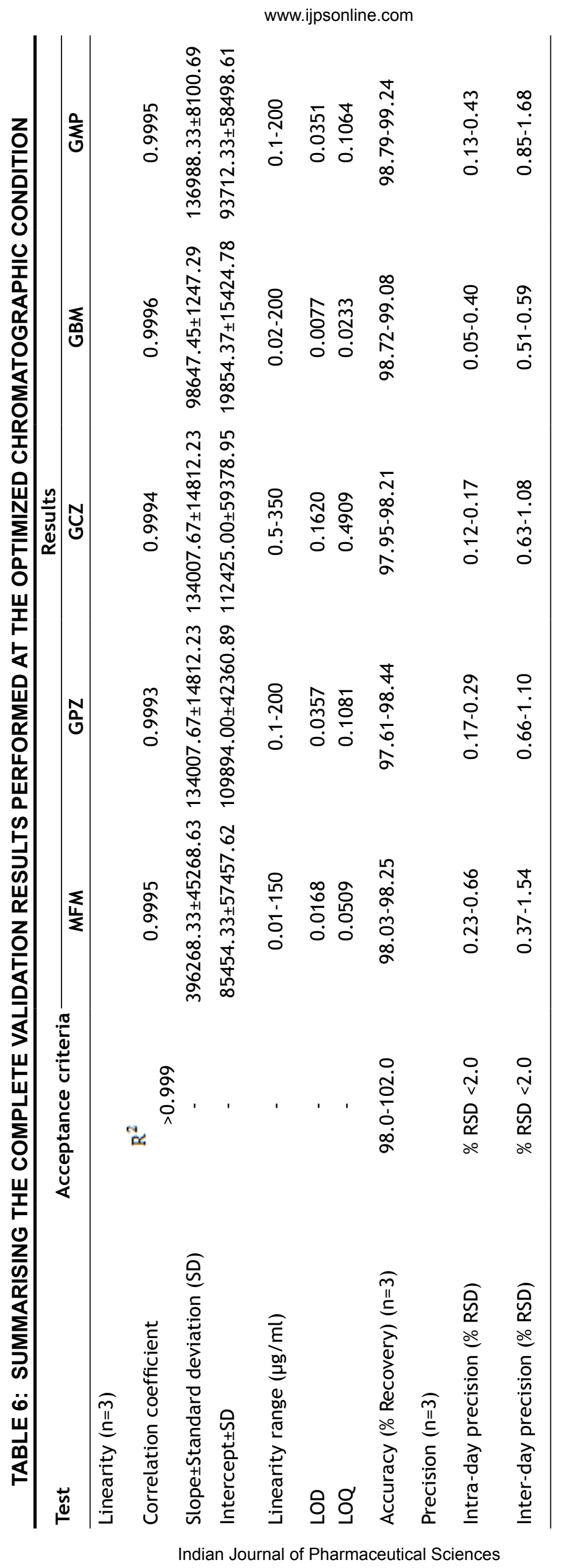


TABLE 7: RESULTS FOR ASSAY OF FORMULATIONS

\begin{tabular}{|c|c|c|c|c|c|}
\hline Formulation & Manufacturer (India) & Analyte & Labelled claim (mg) & Amount found (mg) & Recovery (\%) \\
\hline \multirow{2}{*}{ Glipimet Forte Tab } & \multirow{2}{*}{ Sun Pharma } & MFM & 500 & 492.75 & 98.55 \\
\hline & & GPZ & 5 & 4.89 & 97.78 \\
\hline \multirow{2}{*}{ Bionase-MF Tab } & \multirow{2}{*}{ Biochem } & MFM & 500 & 487.05 & 97.41 \\
\hline & & GPZ & 5 & 4.86 & 97.25 \\
\hline \multirow{2}{*}{ Glygard-M Tab } & \multirow{2}{*}{ Cipla } & MFM & 500 & 493.90 & 98.78 \\
\hline & & $\mathrm{GCZ}$ & 80 & 77.78 & 97.22 \\
\hline \multirow{2}{*}{ Glycigon-Msr Tab } & \multirow{2}{*}{ Aristo } & MFM & 500 & 493.50 & 98.7 \\
\hline & & $\mathrm{GCZ}$ & 80 & 78.35 & 97.94 \\
\hline \multirow{2}{*}{ Gliconil-M Tab } & \multirow{2}{*}{ Biochem } & MFM & 500 & 492.70 & 98.54 \\
\hline & & GBM & 5 & 4.87 & 97.42 \\
\hline \multirow{2}{*}{ Glucored Forte Tab } & \multirow{2}{*}{ Sun Pharma } & MFM & 500 & 494.15 & 98.83 \\
\hline & & GBM & 5 & 4.88 & 97.54 \\
\hline \multirow{2}{*}{ Azulix-MF Tab } & \multirow{2}{*}{ Torrent } & MFM & 500 & 485.35 & 97.07 \\
\hline & & GMP & 2 & 1.98 & 98.77 \\
\hline \multirow{2}{*}{ Gemer-2 Tab } & \multirow{2}{*}{ Sun Pharma } & MFM & 500 & 493.35 & 98.67 \\
\hline & & GMP & 2 & 1.94 & 97.14 \\
\hline
\end{tabular}

the retention times and the percentage $(\%)$ recoveries were not much affected by varied conditions during the robustness study and the \% RSD is $<2.0$ indicating the method robustness.

The \% RSD of the assay from the solution stability and mobile phase bench top stability experiments was within $2 \%$ up to $24 \mathrm{~h}$ (Table S5). The results of the solution stability and mobile phase bench top stability studies confirm that the sample solutions and mobile phase used during the analysis were stable up to $24 \mathrm{~h}$.

The proposed method was applied to the available formulations and the percentage recoveries were calculated (Table 7).

Statistically based experimental design has proven as an important methodology in the optimization of the simultaneous determination of MFM, GPZ, GCZ, GBM and GMP. The significant variables were optimized by employing CCD which provides the sensitivity of the chromatographic responses to the interactions of the selected variables. The present approach maximises the information content of the experimental data with minimum number of experimental runs. The method selectivity, precision, accuracy and robustness with the low time of analysis shows the suitability and better choice for the analysis of the drugs in the complex mixtures. The application of the present method on commercial formulations demonstrated good results and it seems as an option to use on quality control of the formulations in regular use.

\section{Acknowledgements:}

The authors are grateful to University Grants Commission, New Delhi, India for the financial support
(UGC Ref No: 42-674/2013(SR), 2013) and also M/S GITAM University, Visakhapatnam for providing research facilities.

\section{Conflicts of interest:}

The authors declared no conflict of interest.

\section{REFERENCES}

1. Al-Rubeaan K, Youssef AM, Ibrahim HM, Al-Sharqawi AH, AlQumaidi H, AlNaqeb D, et al. All-cause mortality and its risk factors among type 1 and type 2 diabetes mellitus in a country facing diabetes epidemic. Diabetes Res Clin Pract 2016;118:130-9.

2. Olokoba AB, Obateru OA, Olokoba LB. Type 2 diabetes mellitus: a review of current trends. Oman Med J 2012;27(4):269-73.

3. ICH Q8 (R2) Pharmaceutical development, International conference on harmonisation of technical requirements for registration of pharmaceuticals for human use. International Conference on Harmonization; 2009.

4. Rozet E, Lebrun P, Hubert P, Debrus B, Boulanger B. Design spaces for analytical methods. Trends Analyt Chem 2013;42:157-67.

5. Peterson JJ. A Bayesian approach to the ICH Q8 definition of design space. J Biopharm Stat 2008;18(5):959-75.

6. Orlandini S, Pinzauti S, Furlanetto S. Application of quality by design to the development of analytical separation methods. Anal Bioanal Chem 2013;405(2):443-50.

7. Debrus B, Guillarme D, Rudaz S. Improved quality-bydesign compliant methodology for method development in reversed-phase liquid chromatography. J Pharm Biomed Anal 2013;84:215-23.

8. Cela R, Ordonez EY, Quintana JB, Rodil R. Chemometricassisted method development in reversed-phase liquid chromatography. J Chromatogr A 2013;1287:2-22.

9. Kumasaka K, Kojima T, Honda H, Doi K. Screening and quantitative analysis for sulfonylurea-type oral antidiabetic agents in adulterated health food using thin-layer chromatography and high-performance liquid chromatography. 
J Health Sci 2005;51(4):453-60.

10. Ali AK, Hassan AA. Development of a RP-HPLC method for simultaneous determination of some antidiabetic sulfonylurea drugs in bulk and pharmaceutical dosage forms. Int J Pharm Sci Rev Res 2014;25(2):207-10.

11. Venkatesh P, Harisudhan T, Choudhury H, Mullangi R, Srinivas NR. Simultaneous estimation of six anti-diabetic drugsglibenclamide, gliclazide, glipizide, pioglitazone, repaglinide and rosiglitazone: development of a novel HPLC method for use in the analysis of pharmaceutical formulations and its application to human plasma assay. Biomed Chromatogr 2006;20(10):1043-8.

12. Yao J, Shi YQ, Li ZR, Jin SH. Development of a RP-HPLC method for screening potentially counterfeit anti-diabetic drugs. J Chromatogr B 2007;853(1-2):254-9.

13. AbuRuz S, Millership J, McElnay J. The development and validation of liquid chromatography method for the simultaneous determination of metformin and glipizide, gliclazide, glibenclamide or glimperide in plasma. J Chromatogr B 2005;817(2):277-86.
14. Lakshmi KS, Rajesh T. Development and validation of RPHPLC method for simultaneous determination of glipizide, rosiglitazone, pioglitazone, glibenclamide and glimepiride in pharmaceutical dosage forms and human plasma. J Iran Chem Soc 2011;8(1):31-7.

15. Mokhtar HI, Abdel-Salam RA, Hadad GM. Development of a fast high performance liquid chromatographic screening system for eight antidiabetic drugs by an improved methodology of insilico robustness simulation. J Chromatogr B 2015;1399:3244.

16. GuHW,WuHL,LiSS, Yin XL,HuY,XiaH, etal. Chemometricsenhanced full scan mode of liquid chromatography-mass spectrometry for the simultaneous determination of six coeluted sulfonylurea-type oral antidiabetic agents in complex samples. Chemometr Intell Lab Syst 2016;155:62-72.

17. Validation of Analytical Procedures: Text and Methodology Q2 (R1). International conference on harmonisation of technical requirements for registration of pharmaceuticals for human use. International Conference on Harmonization; 2005. 